\title{
HER2 Pro1170Ala polymorphism is associated with decreased survival rate in HER2-negative breast cancer
}

\author{
PILEI SI, YE XU, TAO OUYANG, JINFENG LI, TIANFENG WANG, \\ ZHAOQING FAN, TIE FAN, BENYAO LIN and YUNTAO XIE
}

\begin{abstract}
Key Laboratory of Carcinogenesis and Translational Research (Ministry of Education), Breast Center, Beijing Cancer Hospital and Institute, Peking University Cancer Hospital, Beijing 100142, P.R. China
\end{abstract}

Received August 31, 2015; Accepted January 10, 2017

DOI: $10.3892 / \mathrm{ol} .2017 .5866$

\begin{abstract}
The Pro1170Ala polymorphism is one of the most common polymorphisms of human epidermal growth factor receptor 2 (HER2) and may affect the clinical outcome in breast cancer. Therefore, in the present study, the incidence of the HER2 Pro1170Ala polymorphism was determined in 3,305 female patients with operable primary breast cancer using a DNA-sequencing assay, and the potential association with survival was investigated. Of these 3,305 patients, $29 \%(955 / 3,305)$ were homozygous for the Pro/Pro genotype, $51 \%(1,679 / 3,305)$ were heterozygous for the Pro/Ala genotype and $20 \%(671 / 3,305)$ were homozygous for the Ala/Ala genotype. The frequency of this polymorphism conformed to the Hardy-Weinberg equilibrium $(\mathrm{P}=0.175)$. No significant association between the HER2 Pro1170Ala polymorphism and recurrence-free survival (RFS) or distant recurrence-free survival (DRFS) was identified in the entire cohort of 3,305 patients. HER2 status was available for 3,170/3,305 patients; no significant association between the HER2 Pro1170Ala polymorphism and survival was identified in HER2-positive patients $(n=728)$. However, among the HER2-negative patients $(n=2,442)$, those with the Pro/Ala or Ala/Ala genotype had a significantly decreased RFS [unadjusted hazard ratio (HR), 1.45; 95\% confidence interval (CI), 1.03-2.04; $\mathrm{P}=0.033$ ] and DRFS (unadjusted HR, 1.65; 95\% CI, 1.11-2.44; $\mathrm{P}=0.012$ ) compared with those with the Pro/Pro genotype. Multivariate analysis revealed that the Pro/Ala or
\end{abstract}

Correspondence to: Professor Yuntao Xie, Key Laboratory of Carcinogenesis and Translational Research (Ministry of Education), Breast Center, Beijing Cancer Hospital and Institute, Peking University Cancer Hospital, 52 Fucheng Road, Beijing 100142, P.R. China

E-mail: zlxyt2@bjmu.edu.cn

Abbreviations: HER2, human epidermal growth factor receptor 2; EGFR, epidermal growth factor receptor; ER, estrogen receptor; PR,progesteronereceptor;RFS, recurrence-freesurvival;DRFS, distant recurrence-free survival; HR, hazard ratio; $\mathrm{CI}$, confidence interval

Key words: human epidermal growth factor receptor 2 Pro1170Ala, polymorphism, breast cancer, prognosis
Ala/Ala genotype was an independent unfavorable factor for DRFS (adjusted HR, 1.63; 95\% CI, 1.05-2.53; $\mathrm{P}=0.029$ ) in the subgroup of HER2-negative patients. The results of the present study suggest that patients with HER2-negative breast cancer with the HER2 Pro1170Ala polymorphism variant exhibit a decreased survival outcome.

\section{Introduction}

The human epidermal growth factor receptor 2 (HER2) gene (also known as erbB-2 or neu) is a member of the epidermal growth factor receptor (EGFR) family $(1,2)$. Located on chromosome 17q21, it codes for a transmembrane glycoprotein with tyrosine kinase activity (3). HER2 is markedly homologous with EGFR, which serves an important role in the regulation of cell growth, differentiation and invasion $(2,3)$. It is well documented that HER2 amplification and/or overexpression is associated with a worse clinical outcome in breast cancer (4-9). HER2-targeted therapy, i.e., using trastuzumab, markedly improves the survival outcome of patients with HER2-positive breast cancer (10-13).

We recently reported that the HER2 Ile655Val polymorphism is significantly associated with the survival outcome of patients with HER2-positive breast cancer, indicating that patients with the Val variant exhibit breast cancer with an aggressive phenotype, but are more sensitive to trastuzumab treatment (14). In the present study, another common polymorphism (HER2 Pro1170Ala) of HER2 was investigated. This polymorphism is located in the tail region of the HER2 protein, and codes for either Pro (CCC) or Ala (GCC) at position 1170 (15). Previous studies have suggested that this polymorphism affects HER 2 activity by altering tail construction and function (2,16-18). A previous study indicated that the HER2 Pro1170Ala variant is associated with an increased risk of developing lung cancer in Korean women (19). However, no association between the HER2 Pro1170Ala polymorphism and the risk of developing breast or endometrial cancer was identified in further studies $(15,20-23)$. A recent study identified that the Pro1170Ala polymorphism is associated with a risk of trastuzumab cardiotoxicity (24). Currently, to the best of our knowledge, no investigation has been conducted into whether the HER2 Pro1170Alapolymorphism affects breast cancer survival. 
Therefore, in the present study, the incidence of the HER2 Pro1170Ala polymorphism was determined in a cohort of 3,305 women with operable primary breast cancer, and the association between the HER2 Pro1170Ala polymorphism and survival was investigated; it was further determined whether the HER2 Pro1170Ala polymorphism was associated with survival in HER2-positive and HER2-negative patients, respectively.

\section{Materials and methods}

Patients. A total of 3,430 female patients with operable primary breast cancer (stages I-III) were treated at the Breast Center, Peking University Cancer Hospital (Beijing, China) between January 2005 and October 2011. Of these 3,430 patients, 125 were excluded from the present study, as theHER2 Pro1170Ala genotype was not identified due to the poor quality of the DNA samples of 77 patients and as survival data were not available for 48 patients. Consequently, 3,305 patients were included in the present study. Ages at diagnosis of the patients ranged between 21 and 90 years, with a median age of 50 years. The stage of the tumors was classified according to the tumor-node-metastasis classification of the Union Internationale Contre Le Cancer $(25,26)$. Tumor size was defined as the maximum tumor diameter measured using ultrasound at the time of diagnosis. Tumor grade, tumor size, estrogen receptor (ER) status, progesterone receptor (PR) status and adjuvant therapy were obtained from the review of medical records, and are presented in Table I. This study was conducted in accordance with the ethical principles of the Declaration of Helsinki and approved by the Research and Ethics Committee of Peking University Cancer Hospital. The project number was 2011KT12. All patients provided written informed consent.

HER2 Prol170Ala genotyping. Genomic DNA was isolated from peripheral blood leukocytes using phenol-chloroform. In brief, peripheral blood leukocytes were mixed with equal volumes of a phenol-chloroform mixture to remove protein contaminants, then precipitated with $100 \%$ ethanol. Amplification of DNA fragments was performed using polymerase chain reaction (PCR) using a Gene Cycler $^{\text {TM }}$ thermocycler (Bio-Rad Laboratories, Inc., Hercules, CA, USA) in a 20- $\mu 1$ solution containing $30 \mathrm{ng}$ genomic DNA, $2.5 \mathrm{mM} \mathrm{MgCl}$, $0.8 \mathrm{mM}$ dNTPs, 1.0X PCR buffer, $0.5 \mu \mathrm{M}$ forward and reverse primers, and 1.25 units AmpliTaq DNA polymerase (Promega Corporation, Madison, WI, USA). The reaction conditions were an initial $94^{\circ} \mathrm{C}$ for 5 min to activate Taq DNA polymerase, followed by 35 cycles of denaturation at $94^{\circ} \mathrm{C}$ for $30 \mathrm{sec}$, annealing at $60^{\circ} \mathrm{C}$ for $30 \mathrm{sec}$ and extension at $72^{\circ} \mathrm{C}$ for $45 \mathrm{sec}$, and a final extension at $72^{\circ} \mathrm{C}$ for $10 \mathrm{~min}$. The forward primer sequence was 5'-CCTGCCCTCTGAGACTGATG-3' and the reverse primer sequence was 5'-GTTCCTCTTCCAACGAGG CT-3'. The HER2 Pro1170Ala genotype was detected by direct sequencing in our laboratory. All fragments were sequenced using a BigDye Terminator Cycle Sequencing kit and ABI 3730 automated sequencer (both Applied Biosystems; Thermo Fisher Scientific, Inc., Waltham, MA, USA). HER2 gene (ID 2064) was used as the reference gene with primer sequences 5'-ATGGAGCTGGCGGCCTTGT-3'. In order to avoid potential contamination, each set of PCR contained a negative and 3 positive controls, a negative control without DNA template and 3 positive controls (known Pro/Pro, Pro/Ala or Ala/Ala genotype, respectively) performed simultaneously. A total of $30 \%$ of the cases were genotyped in duplicate and results were fully concordant.

Assessment of HER2 status. HER2 status was obtained from a review of pathology reports. The HER2 status was determined using immunostaining according to a standard method (27): A score of 0 and $1+$ was considered negative and score of $3+$ was considered positive; a score of $2+$ was further evaluated using fluorescence in situ hybridization using a Vysis CLL FISH Probe kit (Abbott Laboratories, Abbott Park, IL, USA), according to the manufacturer's protocol.

Statistical analysis. Statistical analysis was performed using SPSS software for Windows (version 20.0; IBM SPSS, Armonk, NY, USA). The associations between the HER2 Pro1170Ala genotype variants and clinicopathological characteristics in the entire cohort were evaluated using Pearson's $\chi^{2}$ test. Survival curves were derived from Kaplan-Meier estimator analysis and the differences between the curves were compared using log-rank tests. Recurrence-free survival (RFS) was defined as the time between the date of pathological diagnosis and the date of locoregional recurrence or metastasis, distant metastasis or mortality from breast cancer. Distant recurrence-free survival (DRFS) was defined as the time between diagnosis and the occurrence of distant metastasis or mortality, for which breast cancer was the primary or underlying cause. Multivariate survival analysis was performed to identify independent prognostic variables in the patients with HER2-negative breast cancer using tumor grade, tumor size, lymph node status, ER status, PR status, whether adjuvant therapy was used or not and the HER2 Pro1170Ala genotype as covariates. All statistical tests were two-sided, and $\mathrm{P}<0.05$ was considered to indicate a statistically significant difference.

\section{Results}

Patient characteristics. The clinicopathological characteristics of the 3,305 patients examined are presented in Table I. The incidence of the HER2 Pro1170Ala genotype was determined in these 3,305 patients: $29 \%(955 / 3,305)$ were homozygous for the Pro/Pro genotype, $51 \%(1,679 / 3,305)$ were heterozygous for the Pro/Ala genotype and $20 \%(671 / 3,305)$ were homozygous for the Ala/Ala genotype. The frequency of the variants conformed to the Hardy-Weinberg equilibrium $(\mathrm{P}=0.175)$.

No significant association between the Pro1170Ala polymorphism and age at diagnosis, tumor size, tumor grade, lymph node status, ER status, PR status, HER2 status, adjuvant therapy or trastuzumab treatment was identified in this cohort of 3,305 patients (Table I).

Survival outcome is not associated with the HER2 Prol170Ala genotype for the entire cohort. Follow-up data were available for all 3,305 patients; the median follow-up period was 53 months (range, 2-110 months). The estimated 5-year RFS and DRFS in the 3,305 patients were $90.9 \%$ [95\% confidence interval (CI), 89.7-92.1) and 92.4\% (95\% CI, 91.4-93.4), respectively. No significant difference in survival was identified between the HER2 Pro1170Ala genotypes in 
Table I. Association between the HER2 Pro1170Ala genotype and clinicopathological characteristics.

\begin{tabular}{|c|c|c|c|c|c|}
\hline Characteristic & Overall & Pro/Pro, n (\%) & Pro/Ala, n (\%) & Ala/Ala, n (\%) & P-value \\
\hline Total & 3,305 & 955 (29) & $1,679(51)$ & $671(20)$ & $0.175^{\mathrm{a}}$ \\
\hline Age at diagnosis, years & & & & & $0.771^{\mathrm{b}}$ \\
\hline$\leq 40$ & 593 & $174(18)$ & $305(18)$ & $114(17)$ & \\
\hline$>40$ & 2,712 & $781(82)$ & $1,374(82)$ & $557(83)$ & \\
\hline Tumor size, $\mathrm{cm}$ & & & & & $0.547^{\mathrm{b}}$ \\
\hline$\geq 2$ & 1,733 & $499(55)$ & $872(54)$ & $362(57)$ & \\
\hline$<2$ & 1,412 & $403(45)$ & $734(46)$ & $275(43)$ & \\
\hline Unknown & 160 & & & & \\
\hline Tumor grade & & & & & $0.312^{\mathrm{b}}$ \\
\hline $\mathrm{I}$ & 414 & $130(16)$ & $199(14)$ & $85(15)$ & \\
\hline II & 2,045 & $583(72)$ & $1,033(72)$ & $429(73)$ & \\
\hline III & 381 & $99(12)$ & $210(14)$ & $72(12)$ & \\
\hline Unknown & 465 & & & & \\
\hline Lymph nodes & & & & & $0.239^{\mathrm{b}}$ \\
\hline Positive & 1,154 & $323(35)$ & $580(36)$ & $251(39)$ & \\
\hline Negative & 2,030 & $605(65)$ & $1,031(64)$ & $394(61)$ & \\
\hline Unknown & 121 & & & & \\
\hline ER status & & & & & $0.699^{b}$ \\
\hline Positive & 2,290 & $662(72)$ & $1,154(70)$ & $474(72)$ & \\
\hline Negative & 934 & $261(28)$ & $486(30)$ & $187(28)$ & \\
\hline Unknown & 81 & & & & \\
\hline PR status & & & & & $0.636^{\mathrm{b}}$ \\
\hline Positive & 2,040 & $594(64)$ & $1,027(62)$ & $419(63)$ & \\
\hline Negative & 1185 & $328(36)$ & $615(38)$ & $242(37)$ & \\
\hline Unknown & 80 & & & & \\
\hline HER2 status & & & & & $0.941^{\mathrm{b}}$ \\
\hline Positive & 728 & $205(23)$ & $370(23)$ & $153(23)$ & \\
\hline Negative & 2,442 & $696(77)$ & $1247(77)$ & $499(77)$ & \\
\hline Unknown & 135 & & & & \\
\hline Trastuzumab use & & & & & $0.374^{\mathrm{b}}$ \\
\hline Yes & 146 & $44(5)$ & $79(5)$ & $23(3)$ & \\
\hline No & 3,159 & $911(95)$ & $1,600(95)$ & $648(97)$ & \\
\hline Adjuvant therapy & & & & & $0.495^{\mathrm{b}}$ \\
\hline $\mathrm{C}$ & 1,133 & $313(33)$ & $593(35)$ & $227(34)$ & \\
\hline $\mathrm{E}$ & 623 & $189(20)$ & 316 (19) & $118(18)$ & \\
\hline $\mathrm{C}+\mathrm{E}$ & 1,248 & 357 (37) & $620(37)$ & $271(40)$ & \\
\hline None & 301 & $96(10)$ & $150(9)$ & $55(8)$ & \\
\hline
\end{tabular}

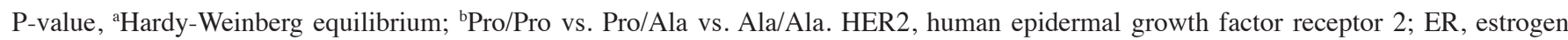
receptor; $\mathrm{PR}$, progesterone receptor; $\mathrm{C}$, chemotherapy; E, endocrine therapy.

the entire cohort of 3,305 patients; patients with the Pro/Ala or Ala/Ala genotype exhibited a similar survival outcome to those with the Pro/Pro genotype [RFS: unadjusted hazard ratio (HR), 1.26; 95\% CI, 0.96-1.65; $\mathrm{P}=0.102$; Fig. 1A; DRFS: unadjusted HR, 1.31; 95\% CI, 0.97-1.79; P=0.082; Fig. 1B].

Survival outcome is associated with the HER2 Proll70Ala genotype for HER2-negative breast cancer, but not HER2-positive breast cancer. HER2 status was available for 3,170/3,305 patients. Of these, 728 (23\%) were diagnosed withHER2-positive breast cancer and 2,442 (77\%) were diagnosed with HER2-negative breast cancer. The association between the HER2 Pro1170Ala polymorphism and survival was analyzed in patients with HER2-positive and HER2-negative tumors, respectively. Among the patients with HER2-positive breast cancer, no significant association was identified between the HER2 Pro1170Ala genotype and survival (RFS: Pro/Ala or Ala/Ala genotype vs. Pro/Pro 

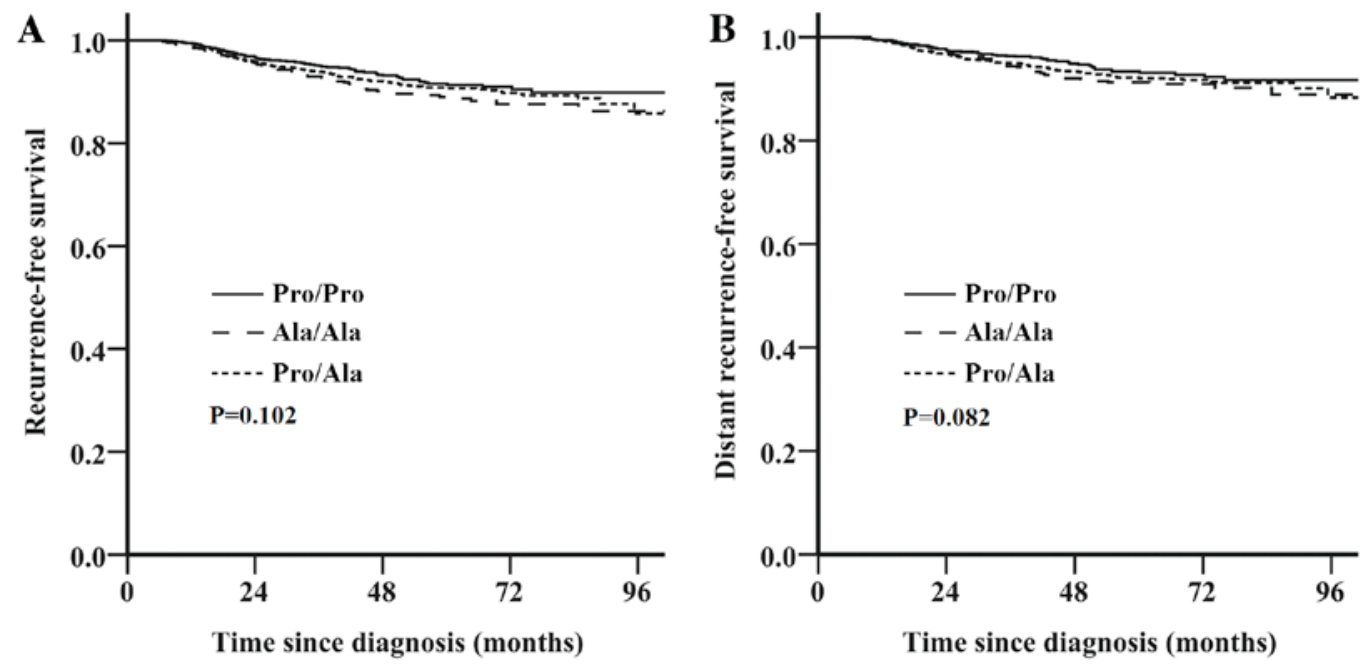

Figure 1. Kaplan-Meier estimator survival curves of $(A)$ recurrence-free survival $(\mathrm{P}=0.102)$ and $(\mathrm{B})$ distant recurrence-free survival $(\mathrm{P}=0.082)$ in the entire study population of 3,305 patients with breast cancer, according to the human epidermal growth factor receptor 2 Prol170Ala genotype.
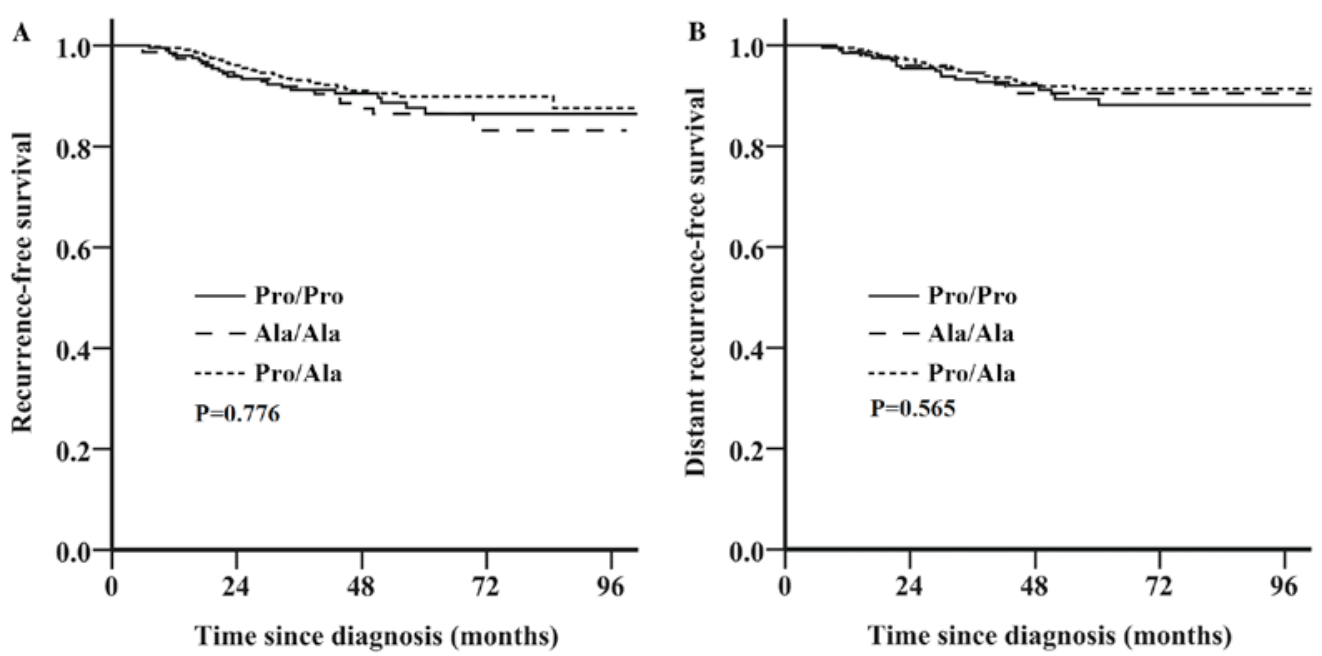

Figure 2. Kaplan-Meier estimator survival curves of $(\mathrm{A})$ recurrence-free survival $(\mathrm{P}=0.776)$ and $(\mathrm{B})$ distant recurrence-free survival $(\mathrm{P}=0.565)$ in the 728 patients with HER2-positive breast cancer, according to human epidermal growth factor receptor 2 Prol170Ala genotype.

genotype; unadjusted HR, 0.93; 95\% CI, 0.56-1.54; P=0.776; Fig. 2A; DRFS: Unadjusted HR, 0.85; 95\% CI, 0.49-1.48; $\mathrm{P}=0.565$; Fig. 2B). By contrast, among patients with HER2-negative tumors, those with the Pro/Ala or Ala/Ala genotype exhibited decreased RFS (unadjusted HR, 1.45; 95\% CI, 1.03-2.04; P=0.033; Fig. 3A) and DRFS (unadjusted HR, 1.65; 95\% CI, 1.11-2.44; $\mathrm{P}=0.012$; Fig. 3B) compared with those with the Pro/Pro genotype. Furthermore, multivariate analysis revealed that the Pro/Ala or Ala/Ala genotype was a near significant unfavorable factor for RFS (adjusted HR, 1.46; 95\% CI, 1.00-2.15; P=0.053; Table II) and a significantly unfavorable factor for DRFS (adjusted HR, 1.63; 95\% CI, 1.05-2.53; $\mathrm{P}=0.029$; Table II) after adjustment for age, tumor grade, tumor size, lymph node status, ER status, PR status and adjuvant therapy.

\section{Discussion}

To the best of our knowledge, the present study is the first to investigate the association between the HER2 Pro1170Ala polymorphism and survival outcome in a large cohort of patients with breast cancer. Although the HER2 Pro1170Ala genotype was not identified to be associated with survival outcome in the entire cohort of 3,305 patients with breast cancer or in the 728 patients with HER2-positive breast cancer, this polymorphism was identified to be significantly associated with survival outcome in the 2,442 patients with HER2-negative breast cancer. The Pro/Ala or Ala/Ala genotype was associated with a decreased RFS and DRFS compared with the Pro/Pro genotype in the HER2-negativesubgroup, and the Pro/Ala or Ala/Ala genotype was identified as an independent unfavorable factor for DRFS, indicating that the Ala variant led to a more aggressive phenotype compared with the Pro variant among HER2-negative patients.

HER2 protein consists of four domains: The extracellular region, the transmembrane domain, the tyrosine kinase domain and the C-terminal tail (28). The Pro1170Ala polymorphism is located in the tail coding region of HER2. The C-terminal tail serves a critical role in the regulation of the enzyme activity of the kinase $(2,16,17,29,30)$. As a non-synonymous coding 
Table II. Multivariate analysis of RFS and DRFS in the 2,442 patients with HER2-negative breast cancer.

\begin{tabular}{|c|c|c|c|c|}
\hline \multirow[b]{2}{*}{ Variable } & \multicolumn{2}{|c|}{ RFS } & \multicolumn{2}{|c|}{ DRFS } \\
\hline & $\mathrm{HR}(95 \% \mathrm{CI})$ & P-value & $\mathrm{HR}(95 \% \mathrm{CI})$ & P-value \\
\hline \multicolumn{5}{|l|}{ Pro1170Ala genotype } \\
\hline Pro/Ala or Ala/Ala vs. Pro/Pro & $1.46(1.00-2.15)$ & 0.053 & $1.63(1.05-2.53)$ & 0.029 \\
\hline \multicolumn{5}{|l|}{ Age, years } \\
\hline$\leq 40$ vs. $>40$ & $1.40(0.96-2.04)$ & 0.081 & $1.42(0.94-2.14)$ & 0.101 \\
\hline \multicolumn{5}{|l|}{ Tumor size, $\mathrm{cm}$} \\
\hline$\geq 2$ vs. $<2$ & $2.71(1.84-4.00)$ & $<0.001$ & $2.58(1.69-3.94)$ & $<0.001$ \\
\hline \multicolumn{5}{|l|}{ Tumor grade } \\
\hline III vs. I/II & $1.17(0.71-1.93)$ & 0.548 & $1.13(0.66-1.96)$ & 0.653 \\
\hline \multicolumn{5}{|l|}{ Lymph nodes } \\
\hline Positive vs. negative & $3.57(2.52-5.06)$ & $<0.001$ & $4.29(2.89-6.36)$ & $<0.001$ \\
\hline \multicolumn{5}{|l|}{ ER status } \\
\hline Negative vs. positive & $1.64(1.04-2.57)$ & 0.033 & $1.66(1.00-2.72)$ & 0.047 \\
\hline \multicolumn{5}{|l|}{ PR status } \\
\hline Negative vs. positive & $1.89(1.22-2.90)$ & 0.004 & $1.82(1.13-2.94)$ & 0.014 \\
\hline \multicolumn{5}{|l|}{ Adjuvant therapy } \\
\hline Therapy vs. none & $1.63(0.78-3.37)$ & 0.191 & $2.10(1.00-4.39)$ & 0.048 \\
\hline
\end{tabular}

RFS, recurrence-free survival; DRFS, distant recurrence-free survival; HER2, human epidermal growth factor receptor 2; HR, hazard ratio; CI, confidence interval; ER, estrogen receptor; PR, progesterone receptor.
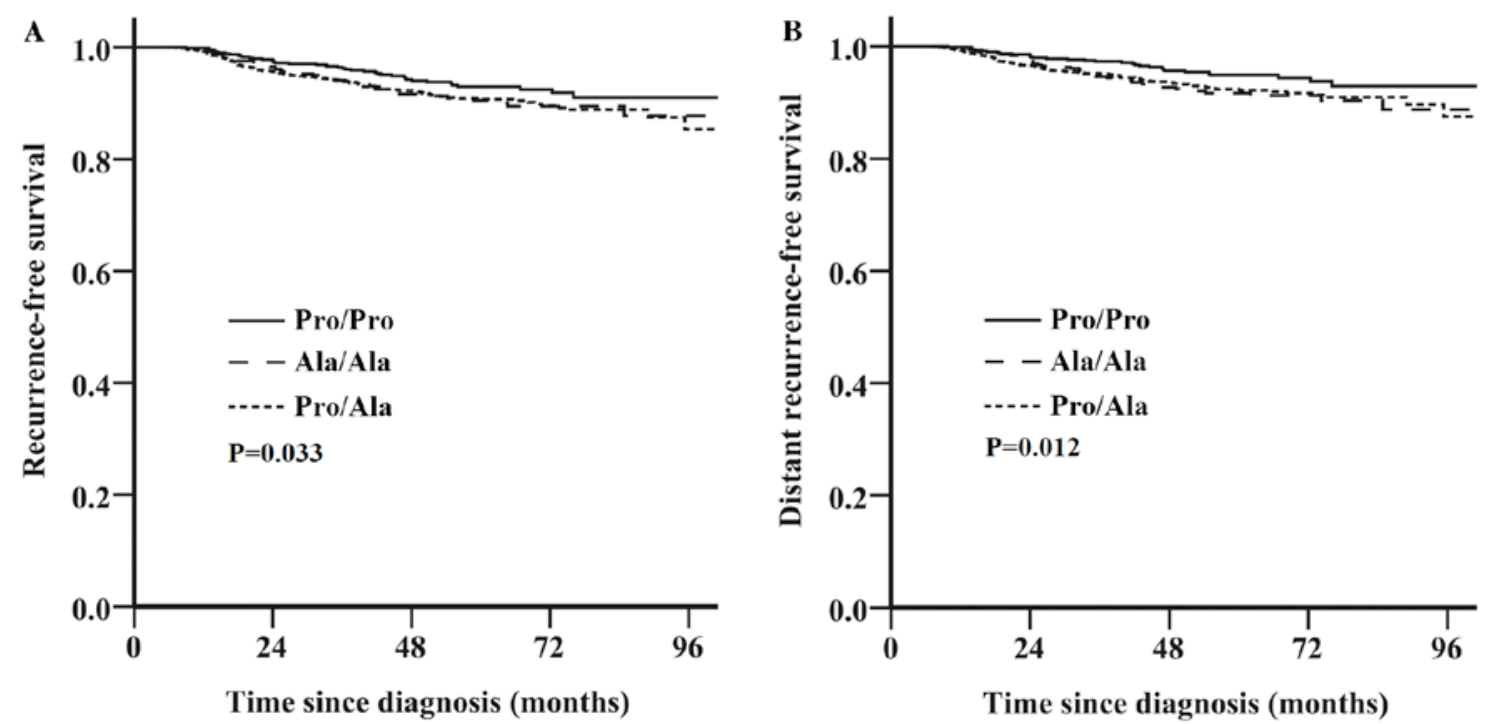

Figure 3. Kaplan-Meier estimator survival curves of $(\mathrm{A})$ recurrence-free survival $(\mathrm{P}=0.033)$ and $(\mathrm{B})$ distant recurrence-free survival $(\mathrm{P}=0.012)$ in the 2,442 patients with HER2-negative breast cancer, according to human epidermal growth factor 2 Pro1170Ala genotype.

variant, the Ala variant of the HER2 Pro1170Ala genotype may alter the spatial conformation of the tail region and may affect tyrosine kinase activity $(18,31)$.

A previous study suggested that the Ala variant increased the risk of lung cancer (19), indicating that the Ala variant may promote HER2 activity. In the present study, an association between the HER2 Pro1170Ala polymorphism and survival was identified in patients with HER2-negative breast cancer, but not in patients with HER2-positive breast cancer. The underlying molecular mechanism for this difference remains unclear; however, one possibility is that, although the HER2 Pro1170Ala polymorphism may alter the HER2 activity, it is not sufficient to influence HER2 activity when the HER2 gene is amplified or overexpressed. Although patients with 
HER2-negative breast cancer have a more favorable survival outcome compared with that of patients with HER2-positive breast cancer, a minority of patients with HER2-negative breast cancer may exhibit metastases after treatment (5-7). Therefore, genotyping of the HER2 Pro1170Ala polymorphism may be useful for identifying the relatively high-risk patients among all patients with HER2-negative breast cancer. In conclusion, the results of the present study demonstrated that, among the patients with HER2-negative breast cancer, the HER2 Pro1170Ala polymorphism is significantly associated with survival, with the Ala variant exhibiting an aggressive phenotype and decreased survival outcome. Further independent studies are required to confirm these findings.

\section{Acknowledgements}

The present study was supported by the 973 project (grant no. 2013CB911004), the National Science and Technology Support Program (grant no. 2014BAI09B08) and the National Natural Science Foundation of China (grant nos. 30973436 and 81071629).

\section{References}

1. Schreiber AB, Libermann TA, Lax I, Yarden Y and Schlessinger J: Biological role of epidermal growth factor-receptor clustering. Investigation with monoclonal anti-receptor antibodies. J Biol Chem 258: 846-853, 1983.

2. Lemmon MA, Schlessinger J and Ferguson KM: The EGFR family: Not so prototypical receptor tyrosine kinases. Cold Spring Harb Perspect Biol 6: a020768, 2014.

3. Akiyama T, Sudo C, Ogawara H, Toyoshima K and Yamamoto T: The product of the human c-erbB-2 gene: A 185-kilodalton glycoprotein with tyrosine kinase activity. Science 232: 1644-1646, 1986.

4. Slamon D, Clark G, Wong S, Levin W, Ullrich A and McGuire W: Human breast cancer: Correlation of relapse and survival with amplification of the HER-2/neu oncogene. Science 235: 177-182, 1987.

5. Toikkanen S, Helin H, Isola J and Joensuu H: Prognostic significance of HER-2 oncoprotein expression in breast cancer: A 30-year follow-up. J Clin Oncol 10: 1044-1048, 1992.

6. Seshadri R, Firgaira FA, Horsfall DJ, McCaul K, Setlur V and Kitchen P: Clinical significance of HER-2/neu oncogene amplification in primary breast cancer. The South Australian Breast Cancer Study Group. J Clin Oncol 11: 1936-1942, 1993.

7. Sjogren S, Inganäs M, Lindgren A, Holmberg L and Bergh J: Prognostic and predictive value of c-erbB-2 overexpression in primary breast cancer, alone and in combination with other prognostic markers. J Clin Oncol 16: 462-469, 1998.

8. Scorilas A, Yotis J, Pateras C, Trangas T and Talieri M: Predictive value of c-erbB-2 and cathepsin-D for Greek breast cancer patients using univariate and multivariate analysis. Clin Cancer Res 5: 815-821, 1999.

9. Ludovini V, Gori S, Colozza M, Pistola L, Rulli E, Floriani I, Pacifico E, Tofanetti FR, Sidoni A, Basurto C, et al: Evaluation of serum HER2 extracellular domain in early breast cancer patients: Correlation with clinicopathological parameters and survival. Ann Oncol 19: 883-890, 2008.

10. Piccart-Gebhart MJ, Procter M, Leyland-Jones B, Goldhirsch A, Untch M, Smith I, Gianni L, Baselga J, Bell R, Jackisch C, et al: Trastuzumab after adjuvant chemotherapy in HER2-positive breast cancer. N Engl J Med 353: 1659-1672, 2005.

11. Gianni L, Dafni U, Gelber RD, Azambuja E, Muehlbauer S, Goldhirsch A, Untch M, Smith I, Baselga J, Jackisch C, et al: Treatment with trastuzumab for 1 year after adjuvant chemotherapy in patients with HER2-positive early breast cancer: A 4-year follow-up of a randomised controlled trial. Lancet Oncol 12: 236-244, 2011.

12. Romond EH, Perez EA, Bryant J, Suman VJ, Geyer CE Jr, Davidson NE, Tan-Chiu E, Martino S, Paik S, Kaufman PA, et al: Trastuzumab plus adjuvant chemotherapy for operable HER2-positive breast cancer. N Engl J Med 353: 1673-1684, 2005.
13. Slamon D, Eiermann W, Robert N, Pienkowski T, Martin M, Press M, Mackey J, Glaspy J, Chan A, Pawlicki M, et al: Adjuvant trastuzumab in HER2-positive breast cancer. N Engl J Med 365: 1273-1283, 2011

14. Han X, Diao L, Xu Y, Xue W, Ouyang T, Li J, Wang T, Fan Z, Fan T, Lin B and Xie Y: Association between the HER2 Ile655Val polymorphism and response to trastuzumab in women with operable primary breast cancer. Ann Oncol 25: 1158-1164, 2014.

15. Tommasi S, Fedele V, Lacalamita R, Bruno M, Schittulli F, Ginzinger D, Scott G, Eppenberger-Castori S, Calistri D, Casadei S, et al: 655Val and 1170Pro ERBB2 SNPs in familial breast cancer risk and BRCA1 alterations. Cell Oncol 29: 241-248, 2007.

16. Fleishman SJ, Schlessinger J and Ben-Tal N: A putative molecular-activation switch in the transmembrane domain of erbB2. Proc Natl Acad Sci USA 99: 15937-15940, 2002.

17. Jorissen RN, Walker F, Pouliot N, Garrett TP, Ward CW and Burgess AW: Epidermal growth factor receptor: Mechanisms of activation and signalling. Exp Cell Res 284: 31-53, 2003.

18. Zhang X, Gureasko J, Shen K, Cole PA and Kuriyan J: An allosteric mechanism for activation of the kinase domain of epidermal growth factor receptor. Cell 125: 1137-1149, 2006.

19. Jo UH, Han SG, Seo JH, Park KH, Lee JW, Lee HJ, Ryu JS and Kim YH: The genetic polymorphisms of HER-2 and the risk of lung cancer in a Korean population. BMC cancer 8: 359, 2008.

20. Benusiglio PR, Lesueur F, Luccarini C, Conroy DM, Shah M, Easton DF, Day NE, Dunning AM, Pharoah PD and Ponder BA: Common ERBB2 polymorphisms and risk of breast cancer in a white British population: A case-control study. Breast Cancer Res 7: R204-R209, 2005.

21. Han W, Kang D, Lee JE, Park IA, Choi JY, Lee KM, Bae JY, Kim S, Shin ES, Lee JE, et al: A haplotype analysis of HER-2 gene polymorphisms: Association with breast cancer risk, HER-2 protein expression in the tumor, and disease recurrence in Korea. Clin Cancer Res 11: 4775-4782, 2005.

22. Breyer JP, Sanders ME, Airey DC, Cai Q, Yaspan BL, Schuyler PA, Dai Q, Boulos F, Olivares MG, Bradley KM, et al: Heritable variation of ERBB2 and breast cancer risk. Cancer Epidemiol Biomarkers Prev 18: 1252-1258, 2009.

23. Tong SY, Ha SY, Ki KD, Lee JM, Lee SK, Lee KB, Kim MK, Cho CH and Kwon SY: The effects of obesity and HER-2 polymorphisms as risk factors for endometrial cancer in Korean women. BJOG 116: 1046-1052, 2009.

24. Stanton SE, Ward MM, Christos P, Sanford R, Lam C, Cobham MV, Donovan D, Scheff RJ, Cigler T, Moore A, et al: Pro1170 Ala polymorphism in HER2-neu is associated with risk of trastuzumab cardiotoxicity. BMC cancer 15: 267, 2015.

25. Wittekind C: 2010 TNM system: On the 7th edition of TNM classification of malignant tumors. Pathologe 31: 331-332, 2010 (In German).

26. Wittekind C: Lymph nodes, tumour deposits, and TNM: Are we getting better? 7th edition of UICC 2010 TNM classification of malignant tumors. Strahlenther Onkol 188: 191-192, 2012 (In German).

27. Wolff AC, Hammond ME, Hicks DG, Dowsett M, McShane LM, Allison KH, Allred DC, Bartlett JM, Bilous M, Fitzgibbons $\mathrm{P}$, et al: Recommendations for human epidermal growth factor receptor 2 testing in breast cancer: American Society of Clinical Oncology/College of American Pathologists clinical practice guideline update. J Clin Oncol 31: 3997-4013, 2013.

28. Franklin MC, Carey KD, Vajdos FF, Leahy DJ, de Vos AM and Sliwkowski MX: Insights into ErbB signaling from the structure of the ErbB2-pertuzumab complex. Cancer Cell 5: 317-328, 2004.

29. Honegger AM, Kris RM, Ullrich A and Schlessinger J: Evidence that autophosphorylation of solubilized receptors for epidermal growth-factor is mediated by intermolecular cross-phosphorylation. Proc Natl Acad Sci USA 86: 925-929, 1989.

30. Alvarez CV, Shon KJ, Miloso M and Beguinot L: Structural requirements of the epidermal growth-factor receptor for tyrosine phosphorylation of Eps8 and Eps15, substrates lacking Src Sh2 homology domains. J Biol Chem 270: 16271-16276, 1995.

31. Wood ER, Truesdale AT, McDonald OB, Yuan D, Hassell A, Dickerson SH, Ellis B, Pennisi C, Horne E, Lackey K, et al: A unique structure for epidermal growth factor receptor bound to GW572016 (Lapatinib): Relationships among protein conformation, inhibitor off-rate and receptor activity in tumor cells. Cancer Res 64: 6652-6659, 2004. 